\title{
INFLUÊNCIA DOS TIPOS DE ÓLEOS E TEMPOS DE FRITURA NA PERDA DE UMIDADE E ABSORÇÃO DE ÓLEO EM BATATAS FRITAS
}

\author{
Influence of the oil type and frying time on the moisture loss and oil absorption by potatoes chips
}

\author{
Neuza Jorge ${ }^{1}$, Vanessa Martins Lunardi ${ }^{2}$
}

\section{RESUMO}

Objetivou-se com este trabalho conhecer a influência dos tipos de óleos e tempos de fritura na perda de umidade e absorção de óleo em batatas fritas. Os experimentos foram conduzidos com frituras de batatas empregando óleos de girassol, milho e soja, submetidos em diferentes tempos, à temperatura de $175^{\circ} \mathrm{C}$. Amostras de batatas fritas foram analisadas por meio das determinações de umidade e teor lipídico, após primeira, quinta, décima e décima-quinta fritura. Análise de variância e teste de Tukey foram aplicados aos dados experimentais a níveis de 1 e 5\% de significância. Verificou-se que batatas quando fritas em óleo de soja absorveram menor quantidade de óleo, diferindo significativamente daquelas fritas nos demais óleos estudados, além de ter obtido maior teor de umidade ao longo de todo o processo. No entanto, para o teor lipídico, batatas fritas em óleos de girassol e milho não diferiram significativamente entre si.

Termos para indexação: óleos vegetais, absorção de óleo, batatas fritas, frituras descontínuas.

\begin{abstract}
The objective of this study was to determine the influence of the oil type and the frying time on oil absorption and moisture loss by potato chips. Sliced potatoes were fried in sunflower, corn or soybean oils, at $175^{\circ} \mathrm{C}$, for 10 minutes and different times. Samples of potatoes were analyzed for moisture and lipid contents after 1, 5, 10 and 15 fryings. Analysis of variance and Tukey test were applied to the experimental data at 1 and $5 \%$ level of significance. It was verified that the soybean oil resulted in smaller absorption by the potatoes, in comparison with the other oils studied, and higher moisture contents in the fried potatoes. Regarding lipid contents, potato chips fried in sunflower and corn oils didn't differ significantly.
\end{abstract}

Index terms: vegetable oils, oil absorption, potatoes chips, discontinuous frying.

(Recebido para publicação em 26 de novembro de 2003 e aprovado em 19 de outubro de 2004)

\section{INTRODUÇÃO}

Alimentos submetidos ao processo de fritura apresentam características sensoriais muito agradáveis, uma vez que o óleo é introduzido no produto, ocupando parte do espaço deixado pela água, sendo que o óleo na fritura apresenta dupla função, por um lado, atua como um meio transmissor de calor e, por outro, chega a ser um novo ingrediente do produto frito ao ser absorvido pelo mesmo (CELLA et al., 2002; DEL RÉ, 2003; POZO-DÍEZ, 1995).

Assim, como resultado da fritura, transformações são verificadas nas propriedades físico-químicas e sensoriais do alimento. Os produtos se tornam crocantes e mais agradáveis em sua textura ao serem mordidos. O processo de fritura também confere ao alimento cor dourada, brilhante e uniforme, melhorando sua apresentação e aumentando sabores e aromas, devido ao próprio óleo ou ao desenvolvimento de novos compostos. A conservação do produto é prolongada pela destruição de microrganismos e enzimas presentes nos alimentos e sua palatabilidade é aumentada como conseqüência da perda de umidade e ganho de gordura (BLUMENTHAL, 1996; GUILLAUMIN, 1988).

No entanto, o processo de fritura aumenta a quantidade de óleo no alimento tornando-o, assim, uma fonte mais concentrada de energia. Este fato isolado é benéfico, assim como a melhoria da qualidade sensorial do alimento. A soma destes dois fatores leva a um maior consumo de calorias na dieta e, conseqüentemente, a um aumento do peso corpóreo, o que sob alguns aspectos pode ser indesejável (BERGER, 1984).

Os possíveis riscos à saúde envolvidos no consumo de óleos aquecidos ou oxidados como predisposição à aterosclerose, ação mutagênica ou carcinogênica têm sido, há muitos anos, comentados e revisados (KUBOW, 1990).

A absorção do óleo pelo alimento oscila entre 10 a $60 \%$, podendo ser influenciada por uma série de parâmetros, os quais atuam sobre as velocidades de transferências de massa e energia entre o óleo e o alimento e que são dependentes do próprio alimento, do óleo e das condições de fritura (SMITH et al., 1985).

1. Professora Doutora do Departamento de Engenharia e Tecnologia de Alimentos - Instituto de Biociências, Letras e Ciências Exatas - Universidade Estadual Paulista - Rua Cristóvão Colombo, 2265 - Jardim Nazareth - 15054-000 - São José do Rio Preto, SP - njorge@ibilce.unesp.br

2. Aluna de Iniciação Científica - Bolsista FAPESP- Instituto de Biociências, Letras e Ciências Exatas - Universidade

Estadual Paulista - Rua Cristóvão Colombo, 2265 - Jardim Nazareth - 15054-000 - São José do Rio Preto, SP. 
A relação superfície/volume do alimento em contato com o meio de fritura é muito importante em relação a absorção de óleo. Cada tipo de alimento frito costuma ter um conteúdo característico de óleo absorvido, dependendo, sobretudo, da distância entre a parte interna e a superfície do alimento. O conteúdo lipídico em alimentos com elevada relação superfície/volume é muito mais elevado do que os que apresentam uma relação menor, como é o caso das batatas chips e batatas palito, respectivamente (PAUL \& MITTAL, 1997).

Muitos alimentos, antes de serem submetidos ao processo de fritura, são empanados com farinha, pão e ovo, sendo que é nesta camada externa onde se dão as reações que conferem características especiais ao produto frito, ao mesmo tempo que funciona como uma barreira protetora do alimento e é onde se produz uma maior absorção de óleo, ainda que a quantidade absorvida dependa do tipo de camada (OLEWNIK \& KULP, 1990).

Alguns autores relatam que cada óleo tem uma diferente cinética de absorção. Em estudo com batatas fritas em óleos de oliva e soja em idênticas condições, foi comprovado que a penetração de óleo no alimento é maior para o óleo de soja atribuindo à maior porcentagem de ácidos graxos insaturados de seus triacilgliceróis livres (VARELA, 1989). Não obstante, em estudos realizados por Varela (1980), ao fritar batatas com óleo de soja, observou-se que a penetração inicial deste óleo na batata é maior do que quando se utiliza o óleo de oliva. Porém, quando o alimento está praticamente pronto, ou seja, com a máxima perda de água, o óleo de oliva foi o que apresentou maior absorção.

Outro aspecto importante que influi no grau de absorção de óleo pelo alimento é a qualidade do óleo. A autoxidação, a oxidação térmica e a polimerização aumentam a viscosidade do meio de fritura, uma vez que, à medida que o óleo vai se alterando, produz-se aumento no tempo de cozimento e, conseqüentemente, maior absorção de óleo por parte do alimento frito (DOBARGANES et al., 2000).

A capacidade calórica do óleo diminui com o uso, a medida que o óleo vai se alterando, formam-se surfactantes que ocasionam aumento no tempo de contato entre o alimento e o óleo e isso faz com que o alimento absorva óleo em excesso e que, a taxa de transferência de calor na superfície do alimento aumente, originando uma penetração máxima de óleo, tornando o alimento totalmente gorduroso ao invés de uma penetração periférica com formação de uma crosta (BLUMENTHAL, 1991).
Quanto às condições de fritura de alimentos, a temperatura é crítica quanto à absorção do óleo e eliminação de água. Temperaturas entre 150 e $180^{\circ} \mathrm{C}$ não tem efeito significativo na absorção (DOBARGANES et al., 2000). Temperaturas muito elevadas aceleram o processo de fritura aumentando a decomposição do óleo. Porém, produzem um alimento super cozido na superfície e um cozimento incompleto no seu interior. Temperaturas muito baixas desenvolvem cores mais claras, permitem uma maior absorção de óleo, obtendo um produto mais gorduroso (POZODÍEZ, 1995).

Conduziu-se este trabalho com objetivo de conhecer a influência dos tipos de óleos vegetais e tempos de fritura na perda de umidade e absorção de óleo em batatas fritas à temperatura de $175^{\circ} \mathrm{C}$.

\section{MATERIAL E MÉTODOS}

\section{a) Amostras}

Foram utilizados para os ensaios de fritura descontínua de batatas os seguintes óleos vegetais refinados: óleo de girassol, óleo de milho e óleo de soja, adquiridos no comércio local.

As batatas do tipo binje recentemente colhidas, também adquiridas no comércio local, foram descascadas, cortadas mecanicamente em fatias $(0,2$ $0,3 \mathrm{~cm}$ de espessura), lavadas e submersas em água até o momento da fritura. Em seguida, foram escorridas, secas e pesadas em balança semi-analítica.

\section{b) Processo de fritura}

Os ensaios de fritura descontínua de batatas foram conduzidos em fritadeira doméstica, marca NKS home, modelo DF - 150/AL, com volume de óleo de $1.600 \mathrm{~mL}$ e relação superfície/volume de $0,2 \mathrm{~cm}^{-1}$. A temperatura empregada foi de cerca de $175^{\circ} \mathrm{C}$, controlada pelo termostato da fritadeira, juntamente com auxílio de termômetro.

Antes de dar início aos ensaios de fritura, o óleo foi submetido ao aquecimento por um período de 10 minutos para o estabelecimento do controle de temperatura na fritadeira.

Quinze lotes, com aproximadamente 300 gramas de batatas cortadas em fatias foram fritos por um período de 10 minutos. Foram empregados intervalos de 25 minutos entre cada operação de fritura, sendo que 5 minutos foram utilizados para reaquecimento do óleo antes de reiniciar cada fritura. Os óleos foram aquecidos por período aproximado de 8,50 horas, com reposição 
de óleo fresco para manter a relação superfície/volume constante, após os tempos de frituras correspondentes a 3,00 e 5,75 horas.

Amostras de $100 \mathrm{~g}$ de batatas fritas foram coletadas após 0,70; 3,00; 5,75 e 8,50 horas de fritura, ou seja, após a primeira, quinta, décima e décima quinta frituras. As batatas fritas foram pesadas, embaladas em folha de alumínio e sacos de polietileno, e estocadas em congelador. Foram também retiradas amostras de óleos originais para análises posteriores da composição em ácidos graxos. Todas as amostras foram descongeladas apenas no momento das análises, as quais foram realizadas em duplicata.

\section{c) Determinações analíticas}

\section{Análise nos óleos iniciais}

- Composição em ácidos graxos: expressa em porcentagem de área, determinada por cromatografia em fase gasosa, utilizando-se cromatógrafo HP 5890 com detector de ionização de chama, coluna de sílica fundida BPX70, 50 m de comprimento, 0,25 $\mu \mathrm{m}$ de diâmetro interno, temperatura programada entre $160-230^{\circ} \mathrm{C}$, taxa de $2^{\circ} \mathrm{C} / \mathrm{min}$, hidrogênio como gás de arraste, usando como referência ésteres metílicos de ácidos graxos da Sigma e Merck para identificação. Os ésteres metílicos foram preparados com metilato de sódio (AENOR, 1991).

\section{Análises nas batatas fritas}

- Teor de umidade: expresso em porcentagem, obtido pela relação entre o peso de água eliminada do produto pelo peso da amostra total, conforme método da AOCS (1990).

- Teor lipídico: expresso em porcentagem, determinado conforme o método descrito pela AOCS (1993).

\section{d) Análise estatística}

Para os estudos da fritura descontínua com reposição de óleo fresco, foi feita a avaliação geral dos seguintes fatores do processo: Óleos (girassol, milho e soja) e Tempos de Fritura $(0,70 ; 3,00 ; 5,75$ e 8,50 horas).

Neste trabalho, os resultados obtidos das determinações analíticas foram submetidos à análise de variância para verificar a influência dos fatores sobre a perda de umidade e a absorção de óleo em batatas fritas, em duas repetições. $\mathrm{O}$ experimento foi realizado em um esquema fatorial $3 \times 4$, com três tipos de óleos e quatro tempos de fritura, no delineamento inteiramente casualizado (GOMES, 2000). As análises de variância e as diferenças entre as médias foram testadas a 1 e $5 \%$ de probabilidade, pelo teste de Tukey, utilizando o programa ESTAT.

\section{RESULTADOS E DISCUSSÃO}

Na Tabela 1 encontra-se a composição em ácidos graxos, em ordem crescente de insaturação, para os três óleos iniciais, ou seja, antes de serem submetidos ao processo de fritura. A composição em ácidos graxos dos óleos, mostra que existem diferenças entre eles. Enquanto os óleos de milho e soja apresentam maiores valores de ácido palmítico (12,00 e 12,66\%, respectivamente), o óleo de girassol apresenta a metade deste valor em sua composição. Por outro lado, os óleos de girassol e milho apresentam valores inferiores de ácido linolênico $(0,15$ e $0,70 \%)$ quando comparados com o óleo de soja (4,52\%). Tais valores apresentados pelos óleos estudados encontram-se dentro dos limites estabelecidos pela legislação brasileira para óleos vegetais refinados (BRASIL, 1999).

A partir da composição em ácidos graxos dos óleos iniciais pode-se observar diferenças entre o grau de insaturação dos óleos analisados, sendo que, neste caso, o óleo que contém maior concentração de ácidos graxos insaturados é o óleo de girassol, apresentando 89,00\%, enquanto que, os óleos de milho e soja obtiveram valores de 85,00 e 83,40\%, respectivamente. O óleo que apresentou maior grau de saturação foi o óleo de soja.

TABELA 1 - Composição em ácidos graxos dos óleos de girassol, milho e soja.

\begin{tabular}{cccc}
\hline \multirow{2}{*}{ Ácidos graxos* $^{*}$} & \multicolumn{3}{c}{ Teor de ácidos graxos (\% de área) } \\
\cline { 2 - 4 } & Girassol & Milho & Soja \\
\hline Ácido palmítico (C16:0) & 6,66 & 12,00 & 12,66 \\
Ácido esteárico (C18:0) & 4,32 & 2,90 & 3,96 \\
Ácido oléico (C18:1n9) & 21,09 & 32,20 & 23,61 \\
Ácido linoléico (C18:2n6) & 67,78 & 52,20 & 55,26 \\
Ácido linolênico (C18:3n3) & 0,15 & 0,70 & 4,52 \\
\hline
\end{tabular}

* Valores obtidos da média de duas determinações. 
Na Tabela 2, pode-se observar as análises de variância das determinações de umidade e teor lipídico das batatas fritas em óleos de girassol, milho e soja, utilizando os valores obtidos ao longo do período de aquecimento de 8,50 horas.

Baseando-se nos resultados da análise de variância para a determinação de umidade (Tabela 2), verifica-se que o teste $F$ foi significativo $(p<0,01)$ para os efeitos principais e para a interação. Então, foi necessário proceder ao desdobramento da interação Óleos x Tempos de Fritura e os resultados obtidos encontram-se na Tabela 3.

De acordo com os dados da Tabela 3, os teores de umidade das batatas não diferiram significativamente entre si para o óleo de girassol ao longo dos tempos de fritura. Já para o óleo de milho, com exceção do tempo de fritura correspondente a 0,70 hora, os valores de umidade também não apresentaram diferença significativa entre si. Em cada tempo de fritura, médias de umidade dos óleos diferiram significativamente entre si, com exceção do tempo de fritura inicial (0,70 hora), para as batatas fritas em óleos de milho e soja. Dentre os óleos utilizados nas frituras de batatas, observa-se que as batatas fritas com óleo de soja apresentaram, em média, maiores teores de umidade ao longo de todo o processo $(11,44 \%)$, seguidas daquelas fritas em óleos de milho $(9,87 \%)$ e girassol $(6,07 \%)$.

TABELA 2 - Análises de variância para umidade e teor lipídico das batatas fritas.

\begin{tabular}{cccc}
\hline \multirow{2}{*}{ Causas de Variação } & \multirow{2}{*}{ G.L. } & \multicolumn{2}{c}{ Quadrados Médios } \\
\cline { 3 - 4 } & & Teor de Umidade & Teor Lipídico \\
\hline Óleos & 2 & $61,0122^{* *}$ & $190,1817^{* *}$ \\
Tempos de Fritura & 3 & $1,8739^{* *}$ & $1,6159^{\mathrm{ns}}$ \\
Óleos x Tempos de Fritura & 6 & $1,3495^{* *}$ & $10,2134^{\mathrm{ns}}$ \\
Resíduo & 12 & 0,1072 & 3,4669 \\
Desvio Padrão & & 0,3274 & 1,8620 \\
Coeficiente de Variação (\%) & & 3,59 & 6,51 \\
\hline
\end{tabular}

** teste significativo $(\mathrm{p}<0,01)$.

${ }^{\mathrm{ns}}$ teste não significativo $(\mathrm{p}>0,05)$.

TABELA 3 - Teores de umidade nas batatas submetidas ao processo de fritura em diferentes óleos e tempos de fritura.

\begin{tabular}{ccccc}
\hline \multirow{2}{*}{ Óleos } & \multicolumn{4}{c}{ Tempos de Fritura (horas) } \\
\cline { 2 - 4 } & $\mathbf{0 , 7 0}$ & $\mathbf{3 , 0 0}$ & $\mathbf{5 , 7 5}$ & $\mathbf{8 , 5 0}$ \\
\hline Girassol & $6,19^{\mathrm{aB}}$ & $5,76^{\mathrm{aC}}$ & $5,85^{\mathrm{aC}}$ & $6,49^{\mathrm{aC}}$ \\
Milho & $11,59^{\mathrm{aA}}$ & $9,25^{\mathrm{bB}}$ & $9,40^{\mathrm{bB}}$ & $9,24^{\mathrm{bB}}$ \\
Soja & $11,33^{\mathrm{aA}}$ & $10,45^{\mathrm{bA}}$ & $11,31^{\mathrm{bA}}$ & $12,68^{\mathrm{aA}}$ \\
\hline a, b (linha) & - & $\begin{array}{l}\text { em cada Óleo, médias de Tempos de Fritura seguidas de mesma letra minúscula, não diferem } \\
\text { A, B, C (coluna) - }\end{array}$ & $\begin{array}{l}\text { entre si pelo teste de Tukey (p > 0,05); } \\
\text { em cada Tempo de Fritura, médias dos Óleos seguidas de }\end{array}$ \\
& diferem entre si pelo teste de Tukey (p > 0,05). &
\end{tabular}

Ciênc. agrotec., Lavras, v. 29, n. 3, p. 635-641, maio/jun., 2005 
As batatas in natura utilizadas neste trabalho continham 83,8\% de umidade e 0,1 \% de teor lipídico. Del Ré et al. (2003) encontraram valores próximos, $86,8 \%$ e $0,4 \%$, respectivamente, para batatas da variedade Monalisa.

Ainda, de acordo com a Tabela 3, os resultados obtidos na análise do teor de umidade, após as frituras, variaram de 5,76 a 12,68\% (valor médio = 9,13\%) para as batatas, independentemente do tipo de óleo e tempo de fritura. A perda de umidade nas batatas fritas corresponde a 89,10\% em relação à batata in natura.

Pelos resultados apresentados na Tabela 2, observa-se que o teste $\mathrm{F}$ foi não-significativo ( $\mathrm{p}>0,05$ ) para o efeito Tempos de Fritura e para a interação Óleos $\mathrm{x}$ Tempos de Fritura, o que indica que os fatores Óleos e Tempos de Fritura agem de modo independente sobre o teor lipídico.

Na Tabela 4 encontram-se as médias de teor lipídico das batatas fritas para os dois fatores estudados. Para o fator Óleos, observa-se pela Tabela 2, que o teste $\mathrm{F}$ foi significativo ( $\mathrm{p}<0,01)$. Logo, os teores lipídicos das batatas fritas em óleos de girassol e milho não diferiram entre si, enquanto que estes apresentaram diferença significativa quando comparados com o teor lipídico das batatas fritas com óleo de soja. Com relação aos óleos estudados, batatas fritas em óleos de girassol e milho apresentaram maiores valores de teor lipídico em relação àquelas fritas com óleo de soja. Para os Tempos de Fritura, observa-se pela Tabela 2 que o teste $F$ foi não-significativo ( $p>0,05)$. Assim, entre os tempos de fritura 0,70 e 8,50 horas, os teores lipídicos oscilaram de 27,87 a 29,26\%, respectivamente, não diferindo significativamente entre si (Tabela 4).

Por outro lado, Sahin et al. (2000), em estudos sobre determinação do teor lipídico em batatas durante fritura intermitente após vários tempos de fritura e diferentes temperaturas, relataram que a absorção de óleo nas batatas aumentou com o tempo de fritura em todas as temperaturas.

A partir do teste de Tukey (Tabela 4), observa-se que o óleo de soja apresentou, em média, menor absorção pelas batatas, diferindo significativamente dos demais óleos. Alguns estudos atribuem esta menor absorção devido à presença de maiores teores de ácidos graxos saturados em sua composição (DAMY, 2001; RANI \& CHAUHAN, 1995; VARELA, 1980, 1989). Neste trabalho, batatas fritas em óleos de girassol e milho obtiveram uma maior absorção em relação às batatas fritas em óleo de soja, tendo esses óleos maiores teores de ácidos graxos insaturados (Tabela 1).

Dos óleos estudados, verifica-se que as batatas fritas em óleo de soja apresentaram maior teor de umidade e menor absorção ao longo do processo, demonstrando que o óleo só é introduzido no produto, uma vez que há espaço deixado pela água liberada durante o processo.

Em estudos realizados por Pozo-Díez (1995), o teor lipídico não foi similar aos valores encontrados por outros autores devido às diferenças existentes no procedimento de fritura empregado, no que se refere ao tempo de fritura, tipo de batata e relação superfície/volume do alimento.

TABELA 4 - Médias de teor lipídico das batatas fritas para os fatores Óleos e Tempos de Fritura.

\begin{tabular}{lc}
\hline \multicolumn{1}{c}{ Fatores } & Teor Lipídico (\%) \\
\hline Óleos & \\
\hline Óleo de girassol & $31,06^{\mathrm{a}}$ \\
Óleo de milho & $31,58^{\mathrm{a}}$ \\
Óleo de soja & $23,00^{\mathrm{b}}$ \\
\hline Tempos de Fritura (horas) & \\
\hline 0,70 & $27,87^{\mathrm{a}}$ \\
3,00 & $28,25^{\mathrm{a}}$ \\
5,75 & $28,79^{\mathrm{a}}$ \\
8,50 & $29,26^{\mathrm{a}}$ \\
\hline
\end{tabular}

a, b - para cada fator, médias seguidas de mesma letra, não diferem entre si pelo teste de Tukey (p > 0,05). 
Um outro aspecto importante que influi no grau de absorção de óleo pelo alimento é a qualidade do óleo. A autoxidação, a oxidação térmica e a polimerização aumentam a viscosidade do meio de fritura, uma vez que, à medida que o óleo vai se alterando, produz-se um aumento no tempo de cozimento e, conseqüentemente, uma maior absorção de óleo por parte do alimento frito (BLUMENTHAL, 1991; GUILLAUMIN, 1988). Pozo-Díez (1995) em seus estudos, mediante análises estatísticas, observou-se que o número de frituras não teve influência sobre o grau de absorção do óleo pelo alimento, assim como a qualidade de óleo e, logicamente, o seu grau de degradação, ou seja, a absorção não estava relacionada com o número de frituras, mas sim com as pequenas variações da temperatura durante o processo de fritura que podem afetar a maior ou menor absorção de óleo.

\section{CONCLUSÕES}

a) Dentre os fatores estudados, observou-se que o fator tipos de óleos foi o que mais influenciou sobre a perda de umidade e a absorção de óleo em batatas fritas à temperatura de $175^{\circ} \mathrm{C}$. As batatas fritas apresentaram, em média, umidade e teor lipídio de 9,13 e $28,55 \%$, respectivamente, o que representa produto final de elevado teor calórico.

b)Verificou-se que batatas quando fritas em óleo de soja absorveram menor quantidade de óleo, diferindo significativamente daquelas fritas nos demais óleos estudados, em conseqüência de ter obtido maior teor de umidade ao longo de todo o processo. No entanto, para o teor lipídico, batatas fritas com óleos de girassol e milho não diferiram significativamente entre si.

\section{AGRADECIMENTOS}

À Fundação de Amparo à Pesquisa do Estado de São Paulo - FAPESP, pela concessão de bolsa de Iniciação Científica e aos Laboratórios da Facultad de Ciencias Químicas y Farmacéuticas, Universidad de Chile pela realização das análises de cromatografia gasosa.

\section{REFERÊNCIAS BIBLIOGRÁFICAS}

\author{
AMERICAN OIL CHEMISTS' SOCIETY. Official \\ methods and recommended practices. 4. ed. \\ Champaign, 1990. v. 2. \\ AMERICAN OIL CHEMISTS' SOCIETY. Official \\ methods and recommended practices. 4. ed. \\ Champaign, 1993. v. 3.
}

ASOCIACIÓN ESPAÑOLA DE NORMALIZACIÓN. Norma UNE 55037-73: catálogo de Normas UNE. Madri, 1991.

Berger, K. G. The practice of frying. Porim Technology, [S.l.], v. 9, n. 5, p. 1-34, 1984.

BLUMENTHAL, M. A new look at the chemistry and physical of deep-fat frying. Food Technology, Oxford, v. 2, p. 68-71, 1991.

BLUMENTHAL, M. M. Frying technology. In: BAILEY, A. E. Bailey's industrial oil \& fat products. New York: John Wiley, 1996. v. 3, p. 429-481.

BRASIL. Resolução no 482, de 23 de setembro de 1999. Regulamento técnico para fixação de identidade e qualidade de óleos e gorduras vegetais. Diário Oficial da União, Brasília, DF, v. 196, Seção I, p. 82-87, 13 out. 1999.

CELLA, R. C. F.; REGITANO-D’ARCE, M. A. B.; SPOTO, M. H. F. Comportamento do óleo de soja refinado utilizado em fritura por imersão com alimentos de origem vegetal. Ciência e Tecnologia de Alimentos, Campinas, v. 22, n. 2, p. 111-116, 2002.

DAMY, P. C. Alterações físico-químicas de óleo de soja e da gordura hidrogenada durante o processo de fritura descontinua de batatas. 2001. $136 \mathrm{f}$. Dissertação (Mestrado em Engenharia e Ciência de Alimentos) - Universidade Estadual Paulista, São José do Rio Preto, 2001.

DEL RÉ, P. V. Comportamento de óleos vegetais em frituras descontínuas de produtos pré-fritos congelados. 2003. 121 f. Dissertação (Mestrado em Engenharia e Ciência de Alimentos) - Universidade Estadual Paulista, São José do Rio Preto, 2003.

DEL RÉ, P. V.; COLTRO, A. L.; MANENTE, J. C. P. P.; MARTI, G. E.; JORGE, N. Influência da relação superfície/volume em frituras de batata palito. Revista do Instituto Adolfo Lutz, São Paulo, v. 62, n. 3, p. 213-219, 2003.

DOBARGANES, M. C.; MÁRQUEZ-RUIZ, G.; VELASCO, J. Interactions between fat and food during deep-frying. European Journal of Lipid Science and Technology, Weinheim, v. 102, p. 521528, 2000.

GOMES, F. P. Curso de estatística experimental. 14. ed. Piracicaba: Nobel, 2000. 477 p. 
GUILLAUMIN, R. Kinetics of fat penetration in food. In: VARELA, G.; BENDER, A. E.; MORTON, I. A. (Eds.). Frying foods: principles, changes, new approaches. Chichester: Ellis Horwood, 1988. p. 82-90.

KUBOW, S. Toxicity of dietary lipid peroxidation products. Trends in Food Science and Technology, Cambridge, p. 67-71, Sept. 1990.

OLEWNIK, M.; KULP, K. Factors affecting performance characteristcs of wheat flour in batters. In: KULP, K.; LOEWE, R. (Eds.). Batters and breading in foods processing. Minnesota: American Association of Cereal Chemistry, 1990. p. 93-116.

PAUL, S.; MITTAL, G. S. Regulating the use of degraded oil/fat in deep-fat/oil food frying. Critical Review in Food Science and Nutrition, Cleveland, v. 37, p. 635-662, 1997.

POZO-DÍEZ, R. M. Estudio del proceso de fritura de alimentos frescos $y$ congelados prefritos: comportamiento del aceite de semilla de girasol de alto contenido en acido oleico. 1995. 338 f. Tese (Doutorado em Farmácia) - Facultad de Farmacia, Universidad de Alcalá de Henares, Espanha, 1995.
RANI, M.; CHAUHAN, G. S. Effect of intermittent frying and frying medium on the quality of potato chips. Food Chemistry, London, v. 54, n. 4, p. 365-368, 1995.

SAHIN, S.; SUDHIR, K. S.; LEVENT, B. Combined effects of frying parameters and oil content on moisture levels in french fries. Journal Food Science and Technology, Trivandrum, v. 37, n. 5, p. 557560, 2000.

SMITH, L. M.; CLIFFORD, A. J.; CREVELING, R.; HAMBLIN, C. L. Lipid content and fatty acid profiles of various deep-fat fried foods. Journal American Oil Chemistry Society, [S.l.], v. 62, p. 996-999, 1985.

VARELA, G. Nutritive aspects of olive oil in the frying process. In: CONGRESS ON THE BIOLOGICAL VALUE OF OLIVE OIL, 3., 1980, La Canea, Grécia. Proceedings... La Canea: [s.n.], 1980. p. 385-402.

VARELA, G. La fritura de los alimentos. Boletin Informativo da Sociedad Española de la Nutrición, [S.l.], v. 1, p. 7-9, 1989. 